\title{
Talent Management and Leadership Reciprocity: The case of the South African Aviation Industry
}

\author{
Nicolene Barkhuizen \\ Department of Industrial Psychology, North-West University, Mmabatho, South Africa, 2745 \\ nicolene.barkhuizen@nwu.ac.za \\ Geraldine Welby-Cooke
}

Department of Human Resource Management, University of Pretoria, South Africa, 2000

Nico Schutte

Department of Public Administration, North-West University, Mmabatho, South Africa, 2745

Karel Stanz

Department of Human Resource Management, University of Pretoria, South Africa, 2000

Doi:10.5901/mjss.2014.v5n9p11

\section{Abstract}

The talent mindset of an organisation is a critical success factor which can enhance its capability in driving its strategic objectives. The main objective of this research was to explore employee perceptions of leadership reciprocity in the application of talent management practices in the aviation industry. An adapted version of the Talent Mindset Index was administered among a convenience sample of employees in the South African Aviation Industry $(N=150)$. The results showed that in general that leaders lack a talent mindset and reciprocity towards talent strategies, talent acquisition practices and talent retention practices. In addition, the leadership commitment towards talent management practices was low. This research highlighted the importance of effectively applying talent management practices in an industry where talented employees are scarce. Therefore leaders need to be equipped with the necessary business acumen to make talent management both a strategic and operation priority in the South African aviation industry.

Keywords: Talent, Talent Management, Talent Mindset, Talent Management Practices, Leadership, Aviation

\section{Introduction}

Organisations worldwide are currently experiencing a complex and dynamic changing environment in which most businesses must compete to remain sustainable. Most of these organisations realise that their competitive advantage lies within their intangible assets, namely employees (Chabault, Hulin \& Soparnot, 2012; Collings \& Mellahi, 2009; Kaye \& Smith, 2012). Talent and brainpower are thus becoming the predominant currency in the new era of globalisation (Cheese, Thomas and Graig, 2008; Tymon, Stumpf \& Doh, 2010; Sahai \& Srivastava, 2012).

However the globalisation and the saturation of markets also pressurise organisations to get hold of people who possibly can add value and contribute towards establishing organisational advantage and differentiation from competitors (Tarique \& Schuler, 2010; Tymon et al., 2010). The effective management of talent thus become a key focus as organisations realise that that their employees play a pivotal role in gaining a true advantage in a fast paced and competitive business environment (Cheese et al, 2008; Huang \& Tansley, 2012; McDonnell, 2011).

Against this background the main objective of this research is to determine the impact of leadership reciprocity behaviour on the perceived execution of talent management practices in the aviation industry. The connection between business leaders' reciprocity and talent management can be an important driver in attracting, developing and retaining talent (Guerci \& Solari, 2012). Kaye and Smith (2012) maintain that if business leaders do not possess the correct mindset towards talent management, they already have a disadvantage in the pursuit of their most valuable talented employees. In fact several South African studies have shown that the extent to which managers apply talent management 
practices in organisations have a significant impact on employees' intention to leave the company (Barkhuizen \& Veldtman, 2012; Du Plessis, Stanz \& Barkhuizen, 2010; Mpofu \& Barkhuizen, 2013; Mtila, Barkhuizen \& Mokgele, 2013).

This article is structured as follows. First we present an overview of the concepts of Talent, Talent Management, Talent Management Practices and Leadership and Talent Management. This is followed by a discussion of the research method employed for this study. Flowing from the method the empirical results of the research are reported. The research concludes with a discussion of the results and recommendations for both practice and future research.

\section{Literature Review}

\subsection{Talent, Talent Management and Talent Management Practices}

Talent can be considered as those people who can add value to the organisation through the application of their skills, abilities and knowledge to the strategic direction of the organisation (lles, Preece \& Chuai, 2010; Preece, Iles \& Chuai, 2011). Talent also includes any employee with the ability to impact the organisation positively now and in the future, with the ability to add value (Goff, 2008). Having the right match between a person with talent and a role in an organisation would therefore be the key to excellent organisational performance (see Lewis \& Heckman, 2006; Sahai \& Srivastava, 2012).

According to Stockley (2005) talent management is a conscious, purposeful approach undertaken to attract, develop and retain people with the aptitude and abilities to meet current and future organisational needs. The management of talent is a concept that focuses on defining both strategic and tactical practices which empower the spontaneous sharing of human capital asset by its employees. Talent management is critical to ensure that an organisation's talent improves operational excellence as well the ability of the organisation to achieve its strategic objectives (Ashton \& Morton, 2005; McDonnell et al., 2010). Essentially the goal of talent management would be to ensure that the right skills are available at the right time and place to meet the strategic objectives of the business (Guerci \& Solari, 2012). Talent management thus operates at a strategic, integrative level and is deeply affected by the framework which leaders of an organisation have regarding the importance of talent to the effectiveness of the business (McDonnell et al., 2010).

Morton (2005) identifies eight categories of talent management initiatives: Recruitment, Retention, Professional Development, Leadership, Performance Management, Feedback, Workforce Planning and Culture. According to Gurthridge, Komm and Lawson (2008), recruitment, development and retention systems and practices is still the key to a successful talent management strategy. Practices can reflect whether there is actually a commitment to talent in terms of whether resources are being allocated to these practices. As mentioned by Lockwood (2006) an allocation of a substantial budget to recruitment indicates ownership and acknowledgement of the importance of talented employees.

Most research studies to date shows that Talent Management practices are poorly applied in South African organisations. Some of the most problematic practices relate to the acquisition and retention of talented employees, performance management and talent development (see Barkhuizen \& Veldtman, 2012; Du Plessis et al., 2010; Mpofu \& Barkhuizen, 2013; Mtila et al., 2013). Moreover the poor application of talent management practices also had an adverse impact on both individual level outcomes such as job satisfaction and motivation as well as organisational level outcomes such as service quality and performance.

\subsection{Leadership and Talent Management}

According to Lawler (2008) senior managers should spend at least 30 to 50\% of their time managing talent in human capital centric organisations. Cheese et al (2008) suggest that leaders should adopt a new talent mindset towards the workplace that is inspired by new leadership approaches, new business strategies and new leadership capabilities. The leadership of the organisation sets the strategic direction of the business and establishes the relevant goals and objectives that the people need to achieve in this regard (Capelli, 2008). Leaders therefore are not only required to understand the impact of talent on the organisation but also to truly believe in the value that exceptional talent can add to achieving objectives. Cheese et al (2008) for example maintain that leaders need to identify and invest in the critical talent that can contribute to the success and growth of an organisation.

However, leaders' commitment to talent management still remains a challenge. Gurthridge et al. (2008) alludes to a study done by McKinsey Consulting where the findings clearly showed that the leaders had a negative impact on the application of talent management practices in the organisation. More specifically, the number one issue was that senior managers do not spend high quality time on talent management. More recently the limited empirical studies in the South 
African context clearly showed that the leaders' orientation towards talent management practices is poor (see Magolego et al. 2013; Mogwere, 2014; Mpofu \& Barkhuizen, 2013).

\section{Research Design}

This research was done using a quantitative approach, as it was considered the best method to address the empirical research objectives posed. More specifically, a survey design was used, as this allows for the gathering of quantifiable information that can then be used to determine the impact of trends, attitudes, and opinions within a specific population (Creswell, 2009).

\subsection{Sampling}

The sample for this study was drawn from an organisation operating within the South African Aviation Industry. This survey was targeted at managerial and human resources staff under the premise that HR supports a talent mindset, whilst line management drives it. The survey was thus distributed to a convenience sample of 508 managers and 50 employees in the human resources field to be completed online. A total of 192 surveys were returned with 150 suitable for analysis, thus representing a response rate of $28 \%$. The demographic breakdowns of the respondents are presented in Table 1 below.

Table 1: Demographic Breakdowns of the Respondents ( $N=150)$

\begin{tabular}{|c|c|c|c|}
\hline Item & Category & Frequency & Percentage \\
\hline \multirow[t]{2}{*}{ Gender } & Male & 88 & 58.7 \\
\hline & Female & 62 & 41.3 \\
\hline \multirow[t]{4}{*}{ Age } & $20-29$ & 16 & 10.7 \\
\hline & $30-39$ & 76 & 50.7 \\
\hline & $40-49$ & 29 & 19.3 \\
\hline & 50 plus & 29 & 19.3 \\
\hline \multirow[t]{4}{*}{ Ethnicity } & Black & 29 & 19.3 \\
\hline & White & 89 & 59.3 \\
\hline & Coloured & 17 & 11.3 \\
\hline & Asian & 11 & 7.3 \\
\hline \multirow[t]{3}{*}{ Home Language } & English & 63 & 42.0 \\
\hline & Afrikaans & 47 & 31.3 \\
\hline & Indigenous & 40 & 26.7 \\
\hline \multirow[t]{2}{*}{ Qualification } & Undergraduate & 87 & 58.0 \\
\hline & Postgraduate & 63 & 42.0 \\
\hline \multirow[t]{5}{*}{ Job Level } & Operational & 42 & 28 \\
\hline & Supervisory & 23 & 15.3 \\
\hline & Specialist & 32 & 21.3 \\
\hline & Senior Management & 27 & 18 \\
\hline & Professional & 26 & 17.3 \\
\hline \multirow[t]{3}{*}{$\begin{array}{l}\text { Years Employed } \\
\text { in Organisation }\end{array}$} & $0-4$ years & 15 & 10.0 \\
\hline & $5-10$ years & 24 & 16.0 \\
\hline & More than 10 years & 111 & 74.0 \\
\hline \multirow[t]{2}{*}{ Basis of Employment } & Permanent & 132 & 88.0 \\
\hline & Part-Time & 18 & 12.0 \\
\hline
\end{tabular}

Table 1 shows that most of the respondents is male (58.7), aged between 30 and 39 years of age (50.7), representative from the White Ethnic Group (59.3) and English speaking (42\%). The respondents were primarily in possession of an undergraduate degree (58\%), employed in operational positions (28\%) for more than 10 years in the organisation (74\%) and on a permanent basis (88\%). 


\subsection{Measurements}

The Human Capital Index (adapted version) of the Human Capital Institute (2008) was used to measure the perceived talent management practices of the organisation. The Index consisted of 28 items and measured seven Talent Management Practices: Management Commitment, Strategy, Talent Acquisition, Performance Management, Talent Responsibility, Talent Development and Talent Retention. Respondents were required to indicate their experiences of the application of the Talent Management practices on a five-point scales ranging from Strongly Disagree (1) to Strongly Agree (5). Previous studies found acceptable internal consistencies for the shortened version of the Talent Mindset Index, ranging from 0.73 to 0.87 (Barkhuizen \& Stanz, 2010).

Demographic information that were gathered included age, gender, ethnicity, job category, business unit and number of hours worked per week. The questionnaire was distributed electronically to the respondents. Participation was voluntary and privacy, confidentiality and anonymity of the participants were respected at all times.

\subsection{Data Analyses}

Statistical analysis was carried out using the SPSS Programme (SPSS Inc., 2012). Statistics utilised included the KaiserMeyer-Olkin (KMO) and Bartlett's Test of Sphericity to determine the sample adequacy and sphericity of the itemcorrelation matrix; exploratory factor analysis to discover and identify the dimensions of the TMI, descriptive statistics (i.e. mean, standard deviation, skewness, kurtosis) and reliability analyses.

\section{Results}

\subsection{Factor and Reliability Analyses}

The TMI obtained a Measure of Sampling Adequacy of 0.856. This is above the recommended guideline of 0.6, which indicates adequacy for factor analysis (Hair, Anderson, Tatham \& Black, 2010). An exploratory factor analysis using the Principle Component Factoring extraction method was performed on the 28 items of the Talent Mindset Index. The Factor Analysis initially resulted in seven factors. However a closer inspection of the pattern matrix indicated the items primarily loaded onto three factors. A Principle Factor Analysis was done by using the Direct Oblimin Rotation to specify the three factors. Five items were excluded due to low and problematic factor loadings. The three factors were labelled Talent Strategies (Factor 1), Talent Acquisition and Retention (Factor 2) and Management Commitment (Factor 3). The Talent Strategies Factor included talent management aspects relating to Talent Development, Performance Management and general Talent Management strategies. The three factors explained $48.478 \%$ of the variance. The Pattern Matrix is shown below in Table 2.

Table 2: Pattern Matrix of the TMI Index

\begin{tabular}{|l|c|c|c|}
\hline & $\begin{array}{c}\text { Talent } \\
\text { Strategies }\end{array}$ & $\begin{array}{c}\text { Talent Acquisition } \\
\text { \& Retention }\end{array}$ & $\begin{array}{c}\text { Management } \\
\text { Commitment }\end{array}$ \\
\hline TMI1 & -.164 & .016 & .723 \\
\hline TMI2 & .233 & .184 & .343 \\
\hline TMI5 & .241 & .254 & .410 \\
\hline TMI6 & .581 & .228 & .122 \\
\hline TMI7 & .513 & .020 & .251 \\
\hline TMI8 & .122 & .562 & .202 \\
\hline TMI9 & .101 & .618 & .108 \\
\hline TMI10 & .026 & .502 & .481 \\
\hline TMI11 & .388 & -.287 & .465 \\
\hline TMI12 & .174 & .122 & .413 \\
\hline TMI13 & .122 & .096 & .673 \\
\hline TMI14 & .165 & .110 & .648 \\
\hline TMI17 & .701 & -.180 & .144 \\
\hline TMI18 & .654 & -.032 & .149 \\
\hline TMI19 & .722 & .063 &. .053 \\
\hline TMI20 & .638 & -.254 & .107 \\
\hline
\end{tabular}




\begin{tabular}{|l|l|l|l|}
\hline TMI21 & .787 & .252 & -.244 \\
\hline TMI22 & .719 & .262 & -.190 \\
\hline TMI23 & .691 & .053 & .045 \\
\hline TMI24 & .518 & -.054 & .237 \\
\hline TMI25 & .339 & .463 & -.091 \\
\hline TMI27 & -.122 & .590 & .050 \\
\hline
\end{tabular}

The results of the Pattern Matrix in Table 2 show that all the items show acceptable factor loadings. The Descriptive Statistics and Reliabilities of the TMI factors are reported in Table 3 below.

Table 3: Descriptive Statistics and Reliabilities of the TMI Factors

\begin{tabular}{|l|c|c|c|c|c|}
\hline & Mean & SD & Skewness & Kurtosis & Cronbach Alpha \\
\hline Talent Strategies & 2.3140 & .67606 & .380 & -.034 & .881 \\
\hline Talent Acquisition and Retention Practices & 2.7333 & .67978 & .047 & -.194 & .678 \\
\hline Management Commitment & 2.5190 & .65610 & .047 & .276 & .771 \\
\hline
\end{tabular}

The results of the mean scores in Table 3 shows that the respondents experienced that leaders in general are not committed to talent management practices in the aviation industry. In addition the results also showed that the organisation lacks talent management strategies and management commitment towards Talent Management. The results further showed acceptable to good reliabilities for the sub-scales. Based on the above results we also did further analyses on item level to explore the items that were problematic and contributed to the low mean scores of the subscales. The results are reported in Table 4 below.

Table 4: Descriptive Statistics and Reliabilities of the items of the TMI

\begin{tabular}{|c|c|c|c|c|c|c|}
\hline & Talent Statements & Mean & SD & Skewness & Kurtosis & Cronbach Alpha \\
\hline TMI1 & $\begin{array}{l}\text { Top Executives belief that better talent results in superior organisational } \\
\text { performance }\end{array}$ & 3.05 & 1.143 & -.065 & -.740 & .904 \\
\hline TMI2 & $\begin{array}{l}\text { Organisation's mission statement support organisation's commitment to } \\
\text { human capital }\end{array}$ & 2.92 & 1.071 & -.071 & -.870 & .899 \\
\hline TMI5 & Executives spend at least 30\% of their time strengthening talent pools & 2.12 & .874 & .802 & .773 & .898 \\
\hline TMI6 & Organisation's strategy drive most effective use of human capital & 2.37 & .930 & .473 & -.403 & .896 \\
\hline TMI7 & $\begin{array}{l}\text { Talent Management systems helps to ensure that talent is focused on } \\
\text { achieving most important strategic and business goals }\end{array}$ & 2.45 & .879 & .435 & -.301 & .897 \\
\hline TMI8 & Executive management bring in new talent if current levels are not sufficient & 2.79 & 1.051 & .002 & -.949 & .899 \\
\hline TMI9 & Organisation always look for new top talent & 2.54 & 1.053 & .452 & -.725 & .901 \\
\hline TMl10 & $\begin{array}{l}\text { Organisation's employee value proposition is compelling and attracts top } \\
\text { talent }\end{array}$ & 2.47 & .925 & .673 & .171 & .898 \\
\hline TMl11 & $\begin{array}{l}\text { Senior management directly involved in performance reviews of the top } \\
\text { performers on regular basis }\end{array}$ & 2.47 & 1.014 & .248 & -.584 & .900 \\
\hline TMI12 & A replicable talent review process is in place & 2.27 & .960 & .640 & .095 & .900 \\
\hline TMI13 & Talent is segmented based on demonstrated categories & 2.41 & .997 & .344 & -.601 & .898 \\
\hline TMI14 & Talent is also assessed on expected future performance and contribution & 2.41 & .991 & .452 & -.355 & .897 \\
\hline TMI17 & Executives directly responsible for strengthening talent pools & 2.66 & 1.134 & .086 & -1.123 & .897 \\
\hline TMI18 & $\begin{array}{l}\text { Managers directly responsible for improving development and growth of } \\
\text { their employees }\end{array}$ & 2.43 & 1.071 & .492 & -.492 & .896 \\
\hline TMl19 & $\begin{array}{l}\text { Managers trained in best practices and latest techniques to develop, } \\
\text { mentor and nurture talent }\end{array}$ & 2.13 & .950 & .789 & .240 & .898 \\
\hline TMI20 & $\begin{array}{l}\text { Employees clearly understand 'who is responsible for talent in the } \\
\text { organisation' }\end{array}$ & 2.11 & .942 & .760 & .033 & .900 \\
\hline TMI21 & Defined strategy for developing talent & 2.31 & .935 & .732 & .491 & .897 \\
\hline TMI22 & Resources are properly allocated for talent development & 2.30 & .988 & .761 & .350 & .897 \\
\hline TMI23 & Talent Development Resources include variety of opportunities & 2.19 & .965 & .888 & .831 & .897 \\
\hline TMI24 & $\begin{array}{l}\text { Organisation has culture that promotes helpful coaching and continuous } \\
\text { learning }\end{array}$ & 2.20 & .912 & .613 & -.062 & .898 \\
\hline TMI25 & Turnover of top talent is half the industry average & 2.56 & .923 & .003 & -.371 & .901 \\
\hline TMI27 & $\begin{array}{l}\text { Different strategies are required for attraction and retention of top black and } \\
\text { women talent }\end{array}$ & 3.30 & 1.169 & -.453 & -.659 & .908 \\
\hline
\end{tabular}


The results of the mean scores in Table 4 show that the respondents experienced that most statements relating to the talent reciprocity behaviour of managers are below average. Aspects of Talent Management that seemed most problematic includes: "Executives spend at least 30\% of their time strengthening talent pools (TMI 5); Managers trained in best practices and latest techniques to develop, mentor and nurture talent (TMI 19); Employees clearly understand 'who is responsible for talent in the organisation' (TMI 20); Talent Development Resources include variety of opportunities and Organisation has culture that promotes helpful coaching and continuous learning (TMI 23)." The only two items that were above average included: "Top Executives belief that better talent results in superior organisational performance (TMI 1) and Different strategies are required for attraction and retention of top black and women talent (TMI 24)."

\section{Discussion and Conclusion}

Currently, there is a tangible shift in the focus of organisations towards talent management. The focus is not only to increase leadership capability but to increase organisational capacity at all levels, focusing on a drive for sustainable operations. The main objective of this research was therefore to explore employee perceptions of leadership reciprocity in the application of talent management practices in the aviation industry.

The results showed that the respondents perceived that the Leaders' mindset towards Talent Management was below average. More specifically the results indicated that the organisation lack talent management strategies and management commitment towards Talent Management. The respondents in particularly perceived that executives do not spend sufficient time in strengthening talent pools; that managers are not trained in best practices and latest techniques to develop, mentor and nurture talent; that employees do not clearly understand 'who is responsible for talent in the organisation'; that Talent Development Resources do not include a variety of opportunities and that the organisation does not have a culture that promotes helpful coaching and continuous learning. The results are in line with previous research that indicated that leaders do not possess an adequate mindset towards the effective implementation of Talent Management Practices in the workplace (see Barkhuizen \& Veldsman, 2012; Magolego et al., 2013; Mpofu \& Barkhuizen, 2013; Mtila et al., 2013).

This study made a number of contributions specifically to academic literature, considerations for the practice of talent management and lastly, for input into future research. From a theoretical point of view this research added to the limited empirical research that exists on Talent Management and Talent Mindset in the South African context. Rrom a practical point of view this research highlighted the leaders' lack of commitment towards Talent Management practices. This is problematic as a lack of talent management practices can lead to the turnover intention of employees. Organisation leaders thus need to be trained to apply the correct mindset towards the effective management of talented employees in the workplace.

This research had some limitations. This study relied solely on self-report measures. The exclusive use of selfreport measures in validation studies may increase the likelihood that at least part of the shared variance between measures can be attributed to method variance. Another significant limitation in this research was the lack of literature and empirical research on Talent Mindset, which made it difficult to interpret the findings. More research should be done to develop a theory for Talent Management and Talent Mindset. A further limitation is the sample size, specifically the sampling procedure in the present study, which has significant limitations in terms of the findings generalised to the total population. Finally, in terms of the research design, future studies should focus on longitudinal designs where inferences regarding cause and effect could be made.

For future research it is recommended that the Talent Mindset Index in its current form should be revised. The current tool is limited in its capability of identifying the touch points where change programs will need to be implemented to address negative practices related to poor mindsets regarding talent in organisations. This conclusion is based on the fact that the instrument displayed a low degree of construct validity in relation to the current methodology. The findings will enable further research into the concept of talent mindset and its linkages in an organisation. This study will thus contribute to subsequent research where the refined and validated talent mindset instrument can be utilised to explore relationships with engagement, wellness, safety and other constructs of interest. Finalising this instrument will allow the opportunity for further research into establishing the relationship between talent mindset and business effectiveness.

In conclusion this research highlighted the importance of a leader's mindset and reciprocity in the effective management of talented employees in the organization. An organisation's view regarding the value of its people or its talent reflects externally and will invariably affect its value proposition and brand in the market. This will in turn affect its ability to attract and retain a talented workforce. Leaders thus need to understand their talent mindset, specifically in relation to the new uncertain environment, in order to truly encapsulate the dynamic nature of talent management and to obtain the rewards resulting from this. 


\section{Acknowledgment}

Permission to use the $\mathrm{HCl}$ Index was obtained from the Human Capital Institute of Africa.

\section{References}

Aston, C. \& Morton, L. (2005). Managing Talent for competitive advantage. Strategic HR Review, 4: 28-31.

Barkhuizen, E.N., \& Veldsman, G. (2012). The impact of Talent Management Practices on the Retention of Employees in an Electricity Supply Company. Poster presented at the $30^{\text {th }}$ International Congress of Psychology, Cape Town.

Boudreau, J.W. \& Ramstad, P.M. (2007). Beyond HR: the new science of human capital. Boston: Harvard Business School press

Cappelli, P. 2008. Talent on Demand: Managing Talent in an Age of Uncertainty. Harvard Busines School Press.

Chabault, D., Hulin, A., \& Soparnot, R. (2012). Talent Management in Clusters. Organisational Dynamics, 41, 327-335.

Cheese, P., Thomas, R.J., \& Craig, E. (2008). The Talent Powered Organisation: strategies for globalization, talent management and high performance. London: Kogan Page.

Collings, D., \& Mellahi, K. (2009). Strategic Talent Management: A Review and Research Agenda. Human Resource Management Review, 19, 304-313.

Creswell, J.W. (2009). Research Design: Qualitative, Quantitative, and Mixed Approached to Research (3rd Ed.). Los Angeles: Sage Publications.

Du Plessis, L., Stanz, K., \& Barkhuizen, E.N. (2010). The relationship between Perceived talent management practices, Perceived Organizational Support POS, Perceived Supervisor Support PSS and Intention to quit amongst Generation Y employees in the Recruitment Sector. Paper presented at the 3rd Annual People and Organization's Conference, Wharton School, McGill University.

Guerci, M., \& Solari, L. (2012). Talent Management Practices in Italy - Implications for Human Resource Development. Human Resource Development International, 15(1), 25-41.

Guthridge, M., Komm, A.B., \& Lawson, E. (2008). Making talent management a strategic priority. The McKinsey Quarterly, 49-59.

Hair, J. F., Black, W. C., Babin, B. J., \& Anderson, R. E. (2010). Multivariate data analysis: a global perspective (7th Ed.). New Jersey: Pearson Education.

Huang, J., \& Tansley, C. (2012). Sneaking through the minefield of Talent Management: Notion of Rhetorical Obfuscation. The International Journal of Human Resource Management, 23(17), 3673-3691.

Human Capital Institute (2008). Human Capital Index for Assessment of Talent Management Practices.

lles, P., Preece, D., \& Chuai, X. (2010). Talent Management as a management fashion in HRD: towards a research agenda. Human Resource Development International, 13(2), 125-145.

Kaye, B., \& Smith, C.P. (2012). Career Development: Shifting from Nicety to Necessity. Training \& Development: 52-55.

Lawler, E.E. (2008). Strategic Talent Management: Lessons learned from corporate World. Madison, WI: Consortium for Policy Research in Education.

Lockwood, N.R. (2006). Talent Management: Driver for Organizational Success. SHRM Research Quarterly, 2-11.

Magolego. H., Barkhuizen, E.N. \& Lesenyeho, D.L. (2013). Talent Management and Job Performance: The Mediating Role of Job Satisfaction. In S.M. Lee \& G. Roodt (Eds.), 30th Pan Pacific Conference, Johannesburg, South Africa (pp. 132-135), ISBN: 1-931649-27-3. PPBA

McDonnell, A. (2011). Still Fighting the War for Talent? Bridging the Science versus the Practice Gap. Journal of Business Psychology, 26, 169173.

McDonnell, A., Lamare, R., Gunnigle, P., \& Lavelle, J. (2010). Developing tomorrow's leaders - Evidence of Global Talent Management in Multinational Enterprises. Journal of World Business, 45, 150-160.

Mogwere, P.G. (2014). The relationship between talent management, work engagement and service orientation of support staff at a higher education institution. Unpublished Masters Dissertation, North-West University.

Morton, L. (2005). Talent Management: A Critical Way To Integrate \& Embed Diversity. [Online] Available from: http://www.workinfo.com/free/Downloads/259.htm

Mpofu. L., \& Barkhuizen, E.N. (2013). The Impact of Talent Management Practices on Employees in a Government Institution. In S.M. Lee \& G.

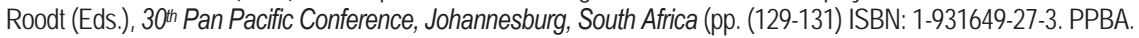

Mtila, J., Barkhuizen, E.N., \& Mokgele, R. (2013). Exploring the Application of Talent Management Practices in a Local Government Institution, 30 th Pan Pacific Business Association Conference, Johannesburg, South Africa.

Preece, D., lles, P., \& Chuai, X. (2011). Talent Management and management fashion in Chinese enterprises: exploring case studies in Beijing. The International Journal of Human Resource Management, 22(16), 3413-3428.

Sahai, S., \& Srivastava, A.K. 2012. Goal/ target setting and performance assessment as tool for talent management, Procedia - Social and Behavioural Sciences, 37, 241-246.

Schuler, R.S., Jackson, S.E., \& Tarique, I. 2011. Global Talent Management and global challenges: Strategic opportunities for IHRM. Journal of World Business, 46, 506-516.

Stockley, D. 2005. Talent management concept: definitions and explanation, [Online] Available:http://derekstockley.com.au/newsletters-05/020talentmanagement.html Accessed 24 February 2014].

Tarique, I., \& Schuler, R.S. 2010. Global Talent Management: Literature Review, Integrative Framework, and Suggestions for Further Research. Journal of World Business, 45, 122-133.

Tymon, W.G., Stumpf, S.A, \& Doh, J.P. 2010. Exploring Talent Management in India: The Neglected Role of Intrinsic Rewards. Journal of Word Business: 45, 109-121. 